\title{
ESCEPTICISMO, ERUDICIÓN Y LIBERTINISMO EN LA MOTHE LE VAYER
}

\author{
A mi hija Irene
}

\section{Carlos GOMEZ RODRfGUEZ}

Resumen: François La Mothe le Vayer (1588-1672) ${ }^{1}$ es uno de los representantes más destacados del libertinismo erudito de la primera mitad del siglo XVII. De hecho, René Pintard en su obra Le libertinage érudit dans la première moi-

1 Sobre La Mothe le Vayer remitimos a las obras siguientes: BOASE, A., The fortunes of Montaigne. A History of the Essays in France, 1580-1669, cap. XVIII :"La Mothe le Vayer: La divine sceptique", Nueva York, Rpt. 1970 (1. 2 edición 1.935), pp. 260-276; PINTARD, René, Le libertinage érudit dans la première moitié du XVIIe. siècle, París, 1943; reed. Ginebra-París, 1983, especialmente pp. 131-146 y 505-538; POPKIN, R., The History of Scepticism from Erasmus to Spinoza, 2." edic., Baltimore, 1979, pp. 92 ss.; BORGHERO, C., La certezza e la storia. Cartesianesimo, pirronismo e conoscenza storica, Milán, 1983, pp. 46-83; BIANCHI, L., Tradizione libertina e critica storica. Da Naudé a Bayle, Milán, 1.988, pp. 45-58; GIOCANTI, S., "La perte du sens commun dans l'oeuvre de La Mothe le Vayerm, en Libertinage et philosophie au XVIIe. siècle, Publications de l'Université de Saint-Étienne, n. ${ }^{\circ} 1$ (1.996), pp. 27-52; PaGanINI, G., Scepsi moderna. Interpretazioni dello scetticismo da Charron a Hume, Cosenza, 1.991; - "Pyrronisme tout pur ou circoncis? La dynamique du scepticisme chez La Mothe le Vayerm, en V.V. A.A., Libertinage et philosophie au XVIle. siècle, n. ${ }^{\circ}$ 2, Publications de l'Université de Saint-Étienne (1997), pp. 7-31; GIOCANTI, S., "La Mothe le Vayer: modes de diversion sceptique», loc. cit., pp. 33-48; OSTROWIECKI, H., "Dialogue et érudition à propos du Dialogue sur le sujet de la divinité de La Mothe le Vayer", loc. cit., pp. 49-62; TAussiG, S., "Gassendi, Naudé et La Mothe le Vayer", loc. cit., pp. 63-74; ChARles-DAUBERT, F., Les libertins érudits en France au XVIIe. siècle, París, 1998, Pp. 51-65; TARANTO, D., "La métamorphose du privé. Reflexions sur l'histoire de la categorie et sur l'usage par Le Vayer", en Libertinage et philosophie, n. 3 (1.999), pp. 45-66; Gros, J.M., "Le masque du scepticisme chrétien chez La Mothe Le Vayern, en Libertinage et philosophie, $\mathbf{n} .^{\circ} 5$ (2001), 83-98; Gouverneur, S., "La Mothe Le Vayer et l'entretien de soin, loc. cit., pp. 99-1 16; GABRIEL, F., "Un mélancolique en personne. Du masque de l'identité", loc. cit., pp. 117-130; GIOCANTI, S., "La Mothe le Vayer: scepticisme libertin et pratique de la contrariété", en V.V. A.A., Le scepticisme au XVIe. et au XVIIe. siecle, París, 2001; GOMEZ RODRfGUEZ, C., "Las lecciones de la historia en Gabriel Naudé y François La Mothe Le Vayern, en prensa. 
tié du XVIIe. siècle ${ }^{2}$ lo sitúa, junto a Gabriel Naudé, Diodati y Pierre Gassendi, como miembro de la tétrade libertine. $Y$, en verdad, la obra de La Mothe, siendo muy disimil en aspectos muy importantes de la de los otros miembros destacados del libertinismo, es perfectamente encuadrable entre los generosos márgenes que la categoría "libertinismo erudito" ha ido adoptando desde la publicación del clásico estudio de Pintard hasta nuestros dias ${ }^{3}$. Sin pretender efectuar una revisión del fenómeno libertino de la primera mitad del siglo XVII, quisiéramos sin embargo señalar algunos rasgos del planteamiento filosófico de Le Vayer que, sin duda, poseen una enorme carga critica respecto a la cultura filosofica tradicional para centrarnos después en el examen más detallado del innegable componente escéptico que recorre su obra, asi como en el alcance y las consecuencias que de él se derivan.

Es unánime la definición del "libertinismo erudito" como un movimiento que se desarrolló al margen de cualquiera de los sistemas filosóficos vigentes en el siglo XVII. Debe entenderse más como una corriente heterogénea en la que, desde posiciones muy diversas, se efectuaba una crítica erudita de las creencias y los dogmas más arraigados en la tradición filosófica y religiosa. En trabajos recientes, como el de F. Charles-Daubert, "Le libertinage érudit: problèmes de définition" " se acepta, en lo esencial, esta definición. Así, tras afirmar la dificultad que entraña la definición de un movimiento filosófico tan complejo, se admiten sin embargo entre las obras de los eruditos libertinos unos rasgos

2 PINTARD, René, Le libertinage érudit dans la première moitié du XVII siècle, París, 1943; reed. Ginebra-París, 1.983.

3 Sobre el libertinismo erudito puede consultarse también BIANCHI, L., Tradizione libertina e critica storica. Da Naudé a Bayle, Milán, 1.988; CHARLES-DAUBERT, F., "Le libertinage érudit : problèmes de définition", en Libertinage et philosophie au XVIIe. siècle, a cargo de MOREAU, P.F. y MCKenna, A. (editores), Publications de l'Université de Saint-Étienne, 1.996, pp. 11-25; -: Les libertins érudits en France au XVIIe. siècle, París, 1998; RIVERA, A., "Libertinismo y escepticismo en la época de las guerras civiles religiosas", Caracteres literarios, Año II, n. ${ }^{\circ} 3$ (1999); GREGORY, T., Genèse de la raison classique de Charron à Descartes, París, 2000.

4 Vid. Supra, nota anterior. Para un estudio del "libertinismo erudito" en su heterogeneidad y complejidad remitimos a los 5 volúmenes aparecidos hasta el momento de la serie "Libertinage et philosophie au XVIIe siècle», de cuya edición hemos dado referencia en la nota 2 y que se subtitulan del modo que sigue a partir del vol 2: "La Mothe le Vayer et Naudé" (1997); vol 3: "Le public et le privé" (1998); vol 4: "Gassendi et les gassendistes et Les passions libertines" (2000) y vol 5: "Les libertins et le masque: simulation et representation" (2001). 
identificatorios comunes que intentaremos resumir lo más brevemente posible: El libertinismo erudito no es un sistema filosófico, ni tan siquiera un corpus doctrinal sistematizable. Por ello, bajo esta categoría podemos encuadrar sin demasiadas dificultades a autores epicúreos, escépticos, deístas, racionalistas, ateos o heterodoxos de todo tipo. No obstante, todos coinciden en la práctica de una cuidadosa erudición al servicio de la crítica antidogmática, antiteológica, así como de creencias muy arraigadas entre las mayorías populares. Suele destacarse también como uno de los rasgos identificatorios de estos autores su actitud profundamente autónoma y libre frente a toda una dogmática avalada por la tradición y el consensus gentium. De este modo, la erudición deviene una suerte de metodología crítica que pretende diseccionar algunas elaboraciones filosóficas, teológicas y políticas tradicionales, para mostrar, si es preciso, su inconsistencia filosófica. En todo caso, si la historia del pensamiento ha asociado este movimiento con la categoría de «libertinismo» ello se debe a la tentativa de estos pensadores por erosionar en sus análisis la representación cristiana de la divinidad, del hombre, de la naturaleza, así como la representación política clásica que mantenía el vínculo entre el derecho divino y el ejercicio del poder. Aunque con lecturas y planteamientos diversos, los libertinos eruditos rastrean en la filosofía antigua (Lucrecio, Séneca, Plutarco, Epicuro, Sexto Empírico, entre muchos otros) para abordar algunos temas tales como la negación de la providencia, la imposibilidad de demostrar la inmortalidad del alma, la vinculación de la religión y la moral con la costumbre, la crítica del antropocentrismo. Todo ello presentado en un estilo si no críptico, sí premeditadamente ambiguo o susceptible de una doble lectura a la que podrá acceder una minoría capaz de apartarse de las opiniones vulgares.

Con todo, la crítica erudita ofrece diferencias muy notables entre unos autores y otros: Si Gabriel Naudé se propone «esquarrer toutes choses au niveau de la raison" 5 , ejerciendo un "racionalismo crítico" ${ }^{6}$ capaz de desenmascarar los errores asociados a muchos dogmas de escuela y a la tradición cultural y de ensayar una nueva comprensión de la naturaleza humana, libre de todo prejuicio filosófico y religioso, aunque él mismo asume una gran influencia del natura-

5 NAUDE, G., Instruction a la France sur la verite de l'bistoire des frères de la Rose-Croix, París, 1.623, Rpt. Gregg. Int., 1.972, p. 64.

6 El término ha sido acuñado por René Pintard (Cfr. Op. cit., pp. 442-476); sobre el "racionalismo" de Naudé Vid. también GOMEZ RodRiguez, C., "Saber y poder político en Gabriel Naudén, Res Publica, 5, 2.000, pp. 111-132, especialmente pp. 129 ss. 
lismo italiano; o si Gassendi transita una senda que Richard Popkin denominaba "el escepticismo constructivo y mitigado" ${ }^{7}$ en el que hace del probabilismo y la elaboración de conjeturas verosímiles el núcleo del conocimiento, frente a modelos científicos que buscaban una certeza epistémica, el caso de La Mothe le Vayer es bien distinto. En su obra, más que en la de ningún otro autor del grupo, se percibe una influencia más amplia del escepticismo. Su metodología crítica resulta ser una aplicación específica del método crítico legado por su admirado Sexto Empírico para oponer a cualquier teoría el necesario antídoto teórico ${ }^{8}$. Precisamente la convicción de que ninguna teoría puede de un modo inequívoco apropiarse de una realidad extremadamente compleja será una de las notas esenciales del planteamiento de nuestro autor. Por otra parte, muchos son los pasajes de su obra en los que se plantea la adopción del habitus escéptico como una condición indispensable para la recepción del cristianismo. El escepticismo, nos dice, al cercenar toda creencia dogmática, deja el alma enteramente preparada para la recepción humilde de la fe cristiana ${ }^{9}$. Sin embargo, el escepticismo de Le Vayer no posee una función precisamente apologética ${ }^{10}$, sino antimetafísica y antiteológica. En efecto, en Le Vayer se antepone una cierta sagesse humana a toda revelación, a todo sistema moral. Se valora la libertad emanada del fuero interno muy por encima de los preceptos emanados de la costumbre, aun reconociendo que ésta sí juega un papel importante en la consecución de la pax y, por ende, en la conservación de la sociedad.

7 Cfr. POPKIN, R., The History of Scepticism from Erasmus to Spinoza, Los Ángeles/Londres, 1.979; trad. Española a cargo de UTRILLA, J.J., La historia del escepticismo desde Erasmo hasta Spinoza, México, 1.983, cap. VII, pp. 201-230.

8 Cfr.: "el escepticismo es la capacidad de establecer antítesis en los fenómenos y en las consideraciones teóricas." (Esbozos pirrónicos, trad. GALlEGo CAO, A. y MUÑOz Diego, T., Madrid, 1.993, p. 53).

9 En el dialogo De la divinité (Dialogues faits à l'imitation des anciens, reed. Fayard, París, 1.988) afirma: "elle [la teología cristiana] n'est point vraiement ou purement une science, qui demanderoit des principes clairs et evidens à nostre entendement, là où elle prend quasi tous les siens des mysteres de nostre foy, laquelle est un vray don de Dieu, et qui surpase entierement la portée de l'esprit humain." (p. 306).

10 Marin Mersenne en La Vérité des Sciences contre les septiques ou Pyrroniens (París, 1.625; Rpt. Stuttgart, 1969, dedicatoria) llega a decir «(les enemis de la vérité des sciences) Ils s'apellent Septiques, et sont gens Libertins, et indignes du nom d'homme qu'ils portent, puisque comme oyseaux funestes de la nuit n'ayans pas la prunelle assez forte pour supporter l'éclat de la vérité ils sacrifient au mensonge, et bornans toute la connoissance des hommes à la seule portée dés sens, et à l'apparence exterieure des choses, nous ravalent indignement à l'état le plus vil, et à la condition la plus basse des bestes les plus stupides et nous depoüillent de l'usage de tout veritable discours, et arraisonnement." Sobre la crítica mersenniana del escepticismo remitimos a JOLY, B., 
II

Como Gassendi, Le Vayer es muy crítico con dos pilares básicos de la visión aristotélica del mundo como son la epistemología y la cosmología. A su modo de ver, la construcción de una ciencia per causas es una empresa absolutamente desproporcionada a la capacidad intelectual humana. Ahora bien, si Gassendi censuraba toda ciencia fundada en el conocimiento de esencias eternas e inmutables para proponer un conocimiento basado en la descripción de la realidad fenoménica ${ }^{11}$, el caso de Le Vayer es sustancialmente distinto. Aquí se entiende la naturaleza como un entramado extraordinariamente complejo y rico que hace vano cualquier esfuerzo humano de teorización, o lo que es lo mismo, cualquier tentativa intelectual de acotar su "obstinada variedad" ${ }^{12}$ a través de esquemas abstractos. Es cierto que en Gassendi también se separa tajantemente el conocimiento de la naturaleza del conocimiento del orden sobrenatural que queda vedado al poder cognoscitivo de los hombres $y$, por tanto, exclusivamente entregado a la experiencia de la fe ${ }^{13}$. Del mismo modo, Gassendi renuncia a una ciencia epistémica y demostrativa para dar paso a un modelo descriptivo de los procesos fenoménicos. Podría decirse entonces que ambos pensadores entenderían que la generación de un conocimiento basado en principios metafísicos constituye un abuso de las operaciones racionales, que por ser desproporcionado a la capacidad humana, no puede sino desembocar en un estéril dogmatismo:

“... c'estoit Dieu seul, qu'on devoit nommer la regle et la mesure de tout ce que contient la Nature (...) nostre humanité est encore dans ce desadvantage de la part des choses, qu'elle n'en reconnoist jamais que la superfice, et les accidens que varient incessament" ${ }^{14}$.

"La figure du sceptique dans La Vérité des sciences de Marin Mersenne», en MOREAU, P.F. (dirección), Le scepticisme au XVIe. Et au XVIIe. siècle, tomo II, París, 2001, pp. 257-266.

1 Vid. Gregory, T., Scetticismo ed empirismo. Studio su Gassendi, Bari, 1961.

12 Cfr. : "...tout ce que contient la Nature est sujet à controverse (...) Certes c'est une chose pitoiable de voir d'un oeil exemt de prevention, comme chacun prend les choses à sa mode, et comme il n'y a presque personne qui n'aime mieux reprendre Dieu, et la Nature, que de reconnoistre ingenuëment l'ignorance où il est." (LA MOTHE LE VAYER, F., Soliloques sceptiques, París, 1.670 , Sol. N. ${ }^{\circ} 12$, pp. $\left.79-80\right)$.

13 Vid. Gregory, T., Genèse de la raison classique de Charron à Descartes, París, 2.000, especialmente Tercera Parte, cap. VI: «Perspectives sur Pierre Gassendi à l'occasion du IVe. Centenaire", pp. 157-190.

14 LA MOTHE LE VAYer, F, De l'opiniatrete, en Dialogues faits à l'imitation des anciens, ed. cit., pp. 367-368. 
Ahora bien, la epistemología gassendiana permite la posibilidad de una ciencia comprensiva de los procesos naturales: Es posible una legalización de los fenómenos en el plano horizontal; puede edificarse una ciencia asentada en un fenomenismo empírico que renuncia a un conocimiento previo de principios de orden metafísico:

"Ea nempe nostrae perspicaciae, cognitionisque conditio est, ut, cum pervidere naturas rerum intimas non possimus, aliquos effectus possimus; contentos nos esse oporteat, si hariolati quidpiam circa illas ex quibusdam effectibus, nostras qualescumque de ipsis notiones adnitamu aliis affectibus accomodare, cum eorum poscimur, seu quomodo a suis naturis originrm habeant, rogamur" ${ }^{15}$.

Así pues, mientras las hipótesis científicas de Gassendi se articulan inductivamente tras la constatación de ciertas regularidades fenoménicas, La Mothe vincula toda comprensión de los fenómenos con la perspectiva adoptada por el sujeto. Es más, a su juicio, cada fenómeno puede ser abordado desde múltiples perspectivas; en consecuencia, no puede privilegiarse una sola sin caer en un conocimiento parcial y desenfocado, en un nuevo dogmatismo. Conocer exige tener en cuenta el pluralismo y la complejidad de cada cuestión y exige convertir en relativa cada una de las hipótesis de conocimiento. Antes velamos que su planteamiento coincidía con el de Gassendi en que las esencias y las causas últimas son incomprensibles, pero ahora debemos constatar que difiere al afirmar que ante la dinámica de los fenómenos naturales, en su inagotable variedad, es imposible buscar constantes, encontrar regularidades. Por ello, si no tomamos la debida cautela, nuestro entendimiento otorgará a la naturaleza una constancia y regularidad que no posee:

«En effet, quelqu'un ne s'est peut-être pas mal imaginé, quà cause que nôtre entendement est d'une substance égale et uniforme, il presuppose dans les ouvrages de la Nature plus d'egalité et plus d'uniformité, quill n'y en a. C'est sur ce fondement qu'on a inventé des figures certaines, tantôt sphériques, tantôt pyramidales, ou coniques dans les Elemens, qui n'y ont peut être nul rapport. La même chose se doit dire de presque toutes les certitudes Mathematiques..." ${ }^{16}$.

15 Gassendi, P., Syntagma, Physica, De loco et duratione rerum, vol. I, p. 207 h; recogido en GREGORY, op. cit., p. 175.

16 LA MOTHE LE VAYER, F., Doute sceptique si l'etude des belles lettres est prefferable à toute autre occupation, Oeuvres, p. 313 (cursiva nuestra) También en el Discours pour montrer que les 
Desde esta perspectiva, la cautela escéptica será el único remedio capaz de liberar al filósofo de las ilusiones derivadas de cualquier modalidad de dogmatismo. Debe tenerse gran cuidado en no conceder la primacía del conocimiento a teoría alguna, en no privilegiar una hipótesis sobre otras, pues esto es lo que otorga al filósofo esa lucidez que Le Vayer denomina la «ignorancia loable»:

"Car nostre ignorance n'est point de ces stupides et grossieres, que les escholes apellent cresses et supines, neque est purae privationis, neque pravae affectionis, c'est une ignorance honorable, et vrayement philosophique, laquelle s'accommodant à l'obscurité de la Nature, et se mesurant à la portée de l'esprit humain, ne promet rien au delà de ses forces. C'est une ignorance discouruë et raisonnable, que je ne veux pas nommer docte, comme le Cardinal Cusan, mais à laquelle neantmoins on ne peut parvenir que par la porte des sciences, qu'elle laisse au dessous de soy, mettant le Sceptique un degré au dessus de tous ces superbes Dogmatiques, et de tous ces Thrasons lettrez" ${ }^{17}$.

Por todo ello, nos parece que el probabilismo de Le Vayer debe ser considerado como un rasgo esencial de una metodología que sólo aspira a efectuar un acompañamiento intelectual de la incesante y "obstinada" mutabilidad de lo real; que no pretende llegar a la hipótesis más probable, sino desplegar un haz de perspectivas que ofrecerá una mayor conciencia de la complejidad de lo real.

Para Le Vayer, la enorme variedad de teorías que en física se ha generado ya desde la Antigüedad, sin que ninguna haya quedado libre de incesantes anomalías emanadas de la propia realidad ni tampoco a salvo de la contradicción derivada de otras teorías distintas, es una prueba bien clara de esa incapacidad del intelecto para someter la naturaleza a esquemas teóricos estables. Como afirma en el Discours pour montrer que les doutes de la philosophia sceptique sont de grand usage dans les sciences:

"Que si descendant du general au particulier de la Physique, nous y considerons la varieté des opinions humaines sur toutes ses parties, nous serons sans doute encore plus confirmés à tenir la suspension de la philosophie

\footnotetext{
doutes de la Philosophie sceptique sont de grand usage dans les sciences, Oeuvres (p. 234), afirma: "...des veritables effets de la Nature, dont tous les Philosophes n'ont eu qu'une connoissance douteuse et imperfaite».

17 LA MOTHE LE VAYER, F, De lignorance louable, Dialogues, p. 223.
} 
sceptique absolument nécessaire. Les principes de cette science naturelle, ses Elemens et tout ce qui en depend, sont autrement envisagés par les uns que par les autres; et les Sectes différentes des Philosophes ont donné plus de combats, et avec plus de violence et plus d'opiniâtreté, sur tout ce qui concerne le monde, et sa constitution; que tous les Conquerans n'ont fait pour '’en rendre les Maitres" ${ }^{18}$.

Por otra parte, de la imposibilidad de conocer las causas, de la incapacidad humana para descifrar los designios de la voluntad divina y las razones del orden de la creación se sigue un cuestionamiento de uno de los vínculos tradicionales que unían la divinidad con la naturaleza y con el destino de los hombres: la providencia, tan asociada por la ortodoxia cristiana con la capacidad para auscultar los fines que Dios ha decretado. Es cierto que Le Vayer protesta su fe y afirma que en las Escrituras hallamos el conocimiento necesario respecto a la obra de Dios, pero, como veremos algo más adelante, su concepción de la religión en tanto cuerpo doctrinal de origen cultural y, por tanto, elaborado por las distintas civilizaciones, hace del cristianismo una religión más, más o menos eficaz en el espacio cultural y político de Occidente. Dejando por ahora esto al margen, veamos antes dos fragmentos muy significativos: uno perteneciente al Discours anteriormente citado y otro al diálogo De la divinité, donde es posible vislumbrar esa crítica libertina de la providencia:

$\mathrm{A} /$ - «La Nature est l'ouvrage des mains de Dieu; et quelle apparence y a$t$-il, de supposer qu'il agisse comme un vil artesan, qui rompt le sien, ou en change la disposition quand il commence à lui déplaire? (...) qu'on doit respecter les Souverains de la Terre jusqu'à ce point, de ne vouloir jamais pénetrer dans leurs secrets, parce qu'aussi bien leur coeur n'est pas reconnoissable non plus que la hauteur du Ciel, et la profondeur de la Terre» ${ }^{19}$.

B/- "...la vérité des choses naturelles n'estant pas necessaire, ny mesme peut estre utile à salut, le Sainct Esprit ne nous l'a aussi jamais revelée; au contraire l'ignorance nous pouvant estre advantageuse, il nous a teu ou desguisé tout ce que les sciences font profession de nous enseigner» ${ }^{20}$.

18 LA MOTHE LE VAYER, F., Discours pour montrer que les doutes de la philosophie sceptique sont de grand usage dans les sciences, Oeuvres, p. 235.

19 Op. cit., p. 233.

20 La Mothe le Vayer, F., De la divinité, Dialogues, p. 310. 
Según esto, no puede haber una ciencia de los fines de la creación, pero Le Vayer también niega el puesto central que el cristianismo otorga al hombre en el escenario de la creación. En un estilo que nos recuerda al Montaigne de la "Apologie de Raimond Sebond" (Essais, II, 12) nos exhorta a desdeñar la presunta superioridad del hombre sobre el resto de las criaturas, relativizando el escalón que separaba al hombre de los animales, como se desprende de los dos fragmentos siguientes:

A/- «comme toutes les opinions de la Physique sont problematiques, puisque celle même de nôtre superiorité à l'égard des autres animaux reçoit tant d'exceptions, et si fortement debatuë» ${ }^{21}$.

B/- «...quelle apparence y a-t'il qu'elle fist giroüetter cette vaste et immense grandeur des cieux autour de ce petit globe de la terre, qui n'est considerée comme un poinct Mathematique, puis que par une petite revolution d'iceluy elle peut si facilement arriver à sa fin?» 22 .

\section{III}

El rechazo de Le Vayer hacia la fundamentación cartesiana de una metodología científica basada en el concepto de razón universal se halla muy presente en el conjunto de su obra. Bastará, sin embargo, prestar atención a dos de sus obras (Petit traité sceptique sur cette commune façon de parler, n'avoir pas le sens commun -Oeuvres, pp. 251-272-y el ya citado Discours pour montrer que les doutes de la philosophie sceptique sont de grand usage dans les sciences - Oeuvres, pp. 220-240-) para poder constatar ya no sólo este extremo, sino el alcance y la aplicación libertina de su propuesta escéptica. La composición del Petit traité juega, al estilo de Erasmo ${ }^{23}$, con el carácter silénico de la oposición entre sentido común y locura. Desde esta perspectiva, la aceptación del sentido común, como síntoma de sabiduría basada en el criterio impuesto por la razón universal no es sino un primer grado de locura, desde

21 Discours..., Oeuvres, p. 236.

22 LA MOTHE LE VAYER, F., De la philosophie sceptique, Dialogues, p. 58.

23 Recuerde el lector la obra de Erasmo, Silenos de Alcibiades. En español remitimos a Escritos de critica religiosa y politica, traducciones de GRANADA, M. A. y PEREZ DE CHINCHON, B., Barcelona, 1996. 
la que se desciende en una pendiente resbaladiza a otros grados aún más profundos: por ejemplo, hacer profesión de sabiduría e intentar impartirla dogmáticamente con la vana pretensión de transformar el mundo. Así lo expresa Le Vayer:

"....il n'y en a point de plus fous, que ceux qui veulent faire les Médecins dans de garnd Hôpital des Incurables, dont les quatre principaux départemens sont l'Europe, l'Asie, l'Afrique, et l'Amerique, avec un cinquiéme vers la terre Australe, qui n'est pas encore ouvert. En effet, comme le premier degré de folie est de s'estimer sage, le second est de faire profession de sagesse, er le troisième de vouloir en consequence réformer le Monde, et guérir la folie des autres" ${ }^{24}$.

La lógica y la retórica contribuyen a provocar ese efecto ilusorio de verdad que emana de la razón. Por eso, la razón, incapaz de efectuar síntesis alguna fidedigna a partir de la diversidad extrema del mundo, no es para La Mothe la divisa que sitúa al hombre por encima de los animales, ya que es un instrumento ineficaz para el dominio de la naturaleza:

«Si nous voulions tenir un fidele registre de tous les mauvais tours que nous a fait cette partie superieure dont nous parlons, peut-être n'y trouverions nous pas dequoi faire tant les glorieux, ni dequoi prendre un si grand avantage que nous faisons sur le reste des animaux, quand nous définissons l'homme un animal raisonnable, pour le bien et avantageusement distinguer de tous les autres. (...) Cependant, si l'on y veut prendre garde un peu plus près, on réconnoîtra bien-tôt le contraire, et que tant s'en faut, c'est la folie qui fait subsister le Monde, lequel apparemment periroit sans son entremise" 25 .

La confianza en la razón dogmática, bajo esta perspectiva, no dará más fruto que un juego de ilusionismo, generará teorías que, a la postre, no serán sino falsedad bajo apariencia de verdad. De ahí que el modelo de hombre sabio es para Le Vayer aquel que posee la lucidez de zafarse de los cantos de sirena de la razón dogmática, del presunto sentido común, para distanciarse de toda afirmación que pretenda erigirse en dogma permanente:

24 La Mothe le Vayer, F., Petit traité.., Oeuvres, p. 265.

25 Op. cit., pp. 263-264. 
"Ainsi il est aisé de conclure que la folie, considérée de ce côté, est aussi utile au monde, que la sagesse y mettroit de confusions irréparables» ${ }^{26}$.

Decir que no hay un sentido común en los hombres es convertir el mundo de las opiniones en una especie de Babel en la que unas teorías triunfan sobre otras por haberse ganado el juicio de la mayoría, convirtiéndose en criterio de autoridad, mas nunca por razones estrictamente epistemológicas. Como no hay una razón universal de la que podamos extraer un criterio de verdad y, por tanto, una metodología capaz de sentar los cimientos de una ciencia demostrativa, son otras las razones que han otorgado la fortuna a unas opiniones y las han implantado en la tradición. La seducción del consentimiento de las mayorías, esto es, la formación de un sentido común, es un hecho tan convencional como la implantación de los rasgos culturales o idiosincráticos en la cultura. De hecho, a la mayoría de los hombres les gusta seguir las opiniones más consensuadas. El sentido común no es más que un acuerdo mayoritario apoyado en esa tendencia natural de los hombres a apoyarse en el asentimiento generalizado. $Y$ es que el espíritu humano es refractario con lo nuevo y suele identificar lo desconocido y lo desacostumbrado con lo falso. No es de extrañar, dice La Mothe, que llamen locura a apartarse del sentido común:

"De cette considération j'entre dans une autre, qui me donne lieu d'admirer l'arrogance et la témerité de l'esprit humain, lors qu'elles lui font condanner, pour être irregulier, tout ce qui lui est nouveau, comme s'il pouvoit être la regle de toutes choses qui les lui font estimer moins communes, quand il n'en a jamais ouï parler, comme si la Nature n'avoit point d'autre étendue que sa connoissance; et qui sont cause qu'il croit qu'on n'a pas le sens commun, aussitôt qu'on s'écarte de sa façon de concevoir, comme si sa sphere d'activité n'avoit point d'autres limites que celles du globe intellectuel, et qu'il eât tenu registre de toutes les opinions humaines, dont il ne sait pas la millième partien ${ }^{27}$.

Pero Le Vayer, lo sabemos ya, otorga el rango de sabiduría a quien sabe reconocer la ilusión del sentido común, de los dogmas y sistemas que en base a él se han fundamentado. De ahí que quienes han pensado por cuenta pro-

26 Op. cit., p. 264.

27 La Mothe le Vayer, F., Petit traicté, Oeuvres, p. 256. 
pia, quienes han mostrado las otras vertientes de la realidad $\mathrm{u}$ otras formas de abordar los temas de siempre han pasado por locos. El carácter silénico del término "locura" es patente una vez más: La sabiduría es enmascarada bajo un rostro falso de locura, aunque lo cierto es que esa locura que nos previene contra las opiniones recibidas es, en verdad, la única sabiduría. Por eso, puede denominarse sin incurrir en contradicción " sabiduría " o "ignorancia loable" a esa actitud que es patrimonio del espíritu escéptico ${ }^{28}$ :

"Il faut que je dise ici en faveur de Démocrite que non seulement les plus grands Philosophes de l'Antiquité ont passé pour fous de leur tems: mais qu'au siècle même où nous sommes, j'ai vû fort peu de grands esprits, et d'hommes de mérite extraordinaire, qui ne soient tombés dans cette diffamation, à l'égard du vulgaire, qui tient toujours pour insensés tous ceux qui s'éloignent de son sens commun, et qui même n'a point de plus ordinaire invective contre des personnes de qui il ne sait que dire, si non que sont des fous, ou qu'ils n'ont pas le sens commun»" ${ }^{29}$.

Le Vayer suele acometer la crítica del dogmatismo a partir del arsenal escéptico contenido en los Esbozos pirrónicos y Adversus Mathematicos de Sexto Empírico. Es frecuente, por tanto, la desautorización de la lógica, la física y la moral como disciplinas entendidas al modo aristotélico ${ }^{30}$; o la crítica de los datos de los sentidos como absolutamente inestables y, así, incapaces de proporcionar un criterio ${ }^{31}$. O la crítica incluso de la capacidad de significación del lenguaje humano, lo cual dificulta toda demostración en el mismo sentido que había apuntađo Sexto Empírico en los Esbozos pirrónicos ${ }^{32}$. Aunque, sin duda, la crítica de Le Vayer alcanzará un interés mucho mayor en esa aplicación peculiar del escepticismo que, en su caso, supone toda una labor erudita de confrontación de

28 Cfr.: Car si nous n'usons d'une exacte suspension d'esprit, il est presque impossible de n'être pas attrapé par les plus grands parleurs, et souvent les moins véritables des hommes. Pline a dit des Oiseaux, que les plus petits étoient ceux qui chantoient davantage, avium loquaciores que minores; il se trouve de même qu'entre les personnes dont nous traitons, celles qui ont le moins de raison, ont presque toujours le plus de babil et d'invincible opiniâtreté." (Discours pour montrer que les doutes..., Oeuvres, p. 232).

29 Petit traité, Oeuvres, p. 255.

30 Vid., por ejemplo, Discours pour montrer que les doutes..., Oeuvres, pp. 230 ss.

31 Vid., por ejemplo, Petit traite..., Oeuvres, p. 266.

32 Vid. Discours pour montrer que les doutes..., Oeuvres, p. 231 y Cfr. con Esbozos pirrónicos, libro II, XI, c. 
costumbres, de teorías, de concepciones de la realidad, para sacar a la luz el proceso de diversificación que constituye el núcleo del conocimiento y deja patente el error que supondría optar por una sola de las teorías confiriéndole el beneficio de la univocidad. Buscar la verdad consiste en relativizar, en destruir los dogmas oponiéndoles el debido antídoto, enfrentándolos con su reverso teórico, consiste en deshacer la ilusión de verdad que se oculta tras todo sistema. Por supuesto Le Vayer tiene cuidado en apartarse de una propuesta escéptica ingenua que, por extrema, caería, a su vez, en el dogmatismo de querer asegurar la imposibilidad de todo conocimiento: "C'est ainsi que le feu qui devore toutes choses se consume lui-même avec elles.» ${ }^{33}$, asegura en el Petit traité. Frente a una concepción del conocimiento que subraya la posibilidad de una certeza epistémica, Le Vayer opone un planteamiento escéptico que fructifica en un conocimiento probable y verosímil. Debemos precisar en sintonía con lo que ya apuntábamos con anterioridad, que la categoría de verosimilitud en Le Vayer adquiere una naturaleza netamente relativista; es una posibilidad junto a otras y no la posibilidad que posee un mayor grado de certeza. Por ello, en nuestro autor cada propuesta verosímil de conocimiento parece convivir en una suerte de simultaneidad con un elenco lo más amplio posible de otras verosimilitudes. Sus obras tratan temas tan importantes como el origen de la moral, o el afianzamiento de las religiones en los distintos espacios culturales, efectuando este ejercicio de diversificación, esto es, poniendo en práctica diferentes perspectivas, desplegando un abanico de posibilidades para intentar demostrar que ninguna posee un mayor peso en la balanza del conocimiento. Al explicar en qué consiste esta tendencia humana de generar teorías verosímiles lo primero que destaca es la incidencia del elemento subjetivo: Así es, la peculiar inclinación de cada uno de los hombres, sus pasiones naturales, la presión de sus intereses, condiciona indudablemente la perspectiva desde la que se ensaya todo conocimiento:

"Les inclinations si dissemblables des hommes, et leurs occupations si contraires, montrent bien qu'ils jugent tout autrement les uns que les autres des choses du Monde» ${ }^{34}$.

El filósofo escéptico debe conocer esto, como sabe de la escasa fiabilidad que poseen los sentidos o de la impotencia de la razón para legalizar una rea- 
lidad inasequible a teoría alguna por mor de su absoluta mutabilidad y, en consecuencia, adoptar una postura filosófica prudente y cautelosa respecto a cualquier hecho de conocimiento.

El escéptico sabe de los errores que han cometido los dogmáticos ya no sólo en ciencias como la física o la historia, sino en disciplinas que tratan de asuntos decisivos para la vida de los hombres, como la moral o la política ${ }^{35}$. No debe colocarse una venda en los ojos ante lo que subyace a los dogmas aceptados por teólogos, políticos y moralistas; debe también dejar al descubierto sus falsas teorías, aunque eso sí, en la soledad de su gabinete o en la confidencia o comunicación restringida al grupo de quienes pueden asimilar verdades inaceptables para la mayoría. Su sabiduría consiste precisamente en apartarse de las ilusiones generadas por el sentido común; en relativizar toda afirmación para así aprehender el carácter complejo y extremadamente proteico de la realidad. Si en Le Vayer el escepticismo proporciona al conocimiento la prudencia de diversificar toda cuestión para obtener el elenco de probabilidades que entraña cualquier problema, la probabilidad o la verosimilitud adquieren una naturaleza peculiar que difiere del estatus que la nueva ciencia otorgaba a estas categorías ${ }^{36}$. En efecto, una afirmación verosímil no es para Le Vayer más que una, entre muchas, de las posibilidades válidas de comprensión de un determinado problema; es una afirmación que no puede perder de vista su carácter no unívoco, que no puede desligarse de la multiplicidad restante de perspectivas, del carácter caleidoscópico que posee la misma realidad; una es tan válida como cualquiera de las otras y, por supuesto, susceptible de modificarse al compás de las propias mutaciones (cambios de perspectiva) de nuestro espíritu. Visto así, el escepticismo es un remedio ${ }^{37}$ que libera al hombre de esa qui-

35 Sobre la política en La Mothe y sus diferencias con Naudé Vid. GOMEZ RoDríGUEZ, "Las lecciones de la historia en Gabriel Naudé y François La Mothe le Vayer", ed. cit., especialmente cap. 3 ("Orontes versus Telamon en el diálogo De la politique : dos concepciones de la política contadas por La Mothe le Vayer»).

36 Nótese la enorme distancia que media entre el planteamiento de La Mothe y el de los renovadores de la ciencia en el siglo XVII. Para ello bastará recordar el valor que los nuevos científicos otorgaban a la justificación de las hipótesis científicas a través de la experimentación así como a la posibilidad de regularizar matemáticamente el orden de los fenómenos, algo que nuestro autor no admite.

37 Cfr.: "Et certes, il y en a si peu qui se servent de la philosophie selon son vray usage, et si peu qui la prennent pour remede, et non pour ornement de leur vie, comme ils devroient faire, qu'il ne se faut pas estonner s'ils attirent sur eux l'envie, et la mauvaise volonté du reste des hommes..." ("Le banquet sceptique», Dialogues, p. 107). 
mera de querer vivir y conocer como si hubiera de suplantar a la divinidad, a quien correspondería en exclusiva un conocimiento absoluto, unívoco y estable. Le devuelve a un estado de conocimiento prudente, flexible y acorde con su propia naturaleza acercándolo con cautela a las diversas probabilidades y, con ello, salvaguardándolo de los errores del dogmatismo y de la obstinación:

"Sçachez que nous ne condamnons point la connoissance des lettres et des sciences, comme vous dites, mais que nous en blasmons seulement l'arrogance, et nous contentons d'en moderer l'opiniastreté» ${ }^{38}$.

Y en el mismo sentido:

"les philosophes ont bien definy l'homme per capable de raison ou de discours, mais non pas de science, laquelle n'estant que des choses universelles et infaillibles n'a nulle convenance avec nostre nature singuliere et caduque...." 39

IV

El planteamiento escéptico de La Mothe le Vayer se alía con la erudición para efectuar la crítica del dogmatismo en terrenos tan sensibles como la moral, la religión o el puesto que el hombre debe ocupar en la realidad. Aquí la erudición consiste ya no sólo en un uso de las fuentes de la Antigüedad clásica, sino en un minucioso esfuerzo de confrontación, de comparación de las costumbres, de las creencias de las diferentes culturas, para destacar el valor exclusivamente relativo y convencional de cada una de ellas. El lector de Le Vayer encontrará en muchas de sus obras cuadros comparativos enormemente prolijos respecto a múltiples aspectos que conforman la vida de los hombres. Así, temáticas tales como las diferentes concepciones de la institución familiar ${ }^{40}$, los usos alimentarios, los tabúes mantenidos por las diferentes culturas $^{41}$, son tratados en un sentido que debe mucho al uso de la categoría "cou-

38 De l'ignorance louable, Dialogues, p. 221.

39 Op. cit., p. 224.

40 Vid., por ejemplo, el diálogo Du mariage, Dialogues, pp. 452 ss.

41 Vid. De la philosophie sceptique, Dialogues, pp. 30 ss. 
tumen efectuado por Michel de Montaigne ${ }^{42}$. Le Vayer ofrece elencos extraordinariamente diversificados en cada una de las materias examinadas para desmentir el carácter absoluto que desde cada una de las culturas se otorga a las costumbres propias, incurriendo, claro está, ya no sólo en el etnocentrismo cultural, sino en el error intelectual de confundir el hábito con la verdad. Basta observar sin prejuicio el comportamiento de los miembros de unas y otras culturas para constatar que unos usos se oponen a otros y que todas defienden sus convenciones como si sólo ellas fueran depositarias de la razón y la justicia. Así, por ejemplo, en el diálogo De l'opiniatreté nuestro autor es extremadamente crítico con la tentativa de querer llevar a las Indias Occidentales nuestros usos $\mathrm{y}$ valores, imponiéndolos de buen o de mal grado:

"Car pour le regard des advantages de la vie, qu'on eust peu penser devoir revenir aux uns et aux autres habitans des deux mondes, comme nous n'avons retiré aucun advantage des moeurs innocentes que nous ont paru dans une façon de vivre exempte de nos depravations, preferant nos vieilles loix corrompuës a celles de la pure Nature; aussi ne faut-il pas penser que tous nos arts penibles, et toutes nos disciplines contentieuses, quand mesme nous les eussions communiquées à ces Ameriquains, les eussent peu rendre plus heureux qu'ils estoient dans une vie exempte de peine, sans soucy, et toute telle que les Poëtes s'efforcent de nous la representer, sub Jove nondum barbato, lors que les hommes sembloient disputer de la felicité avec les essences immortelles" ${ }^{43}$.

El componente libertino implícito en la crítica de La Mothe sube de tono al plantear que la costumbre es el único fundamento al que podemos apelar tanto en los usos más comunes de la vida humana como en la explicación de las más elevadas operaciones morales, estéticas o religiosas:

42 Cfr. Montaigne, M., Essais, I, 23 (“De la coutume et de ne changer aisément une loy receüe» y 31 ( Des cannibales»).

43 La MOTHe Le VAYER, F., De l'opiniatreté, Dialogues, p. 370. No menos crítico es el pasaje siguiente: "Christophe Colomb, auquel à cause de la descouverte du monde nouveau, on veut que celuy-cy soit si fort redevable, avoit au contraire, à le bien prendre, tres mal merité de tout le genre humain, ce que je pensois assez bien justifier par les histoires de ces belles conquestes des Indes Occidentales, où l'on voit que pour satisfaire à l'ambition, à l'avarice, et a toutes les convoitises des hommes de deçà, qui n'en ont esté neantmoins que plus excitées, on a despeuplé et desolé tout l'autre hemisphere, avec des inhumanitez aussi prodigieuses qu'elles sont innombrables.» (Op. cit., pp. 369-370). 
"On voit donc par tout une tres-grande opiniastreté pour la coustume, qu'on peut nommer un cinquiesme Element, voire une autre nature; qui fait que les enfans nouveaux nais ne font que dormir, comme y estans accoustumez dés le ventre de la mere (dit Aristote 5, De Gener. Anim.. 1) et que depuis nous croyons tousjours faire avec raison et justice, ce que nous faisons par usage et imitation" ${ }^{44}$.

El propio Le Vayer deriva este análisis de su lectura del décimo tropo de Enesidemo que es el de "según las formas de pensar, costumbres, leyes, creencias míticas y opiniones dogmáticas" ${ }^{45}$, para concluir en una de las teorías más clásicas del libertinismo erudito: los valores morales no pueden establecerse a priori, son elementos de un sistema exclusivamente convencional. Teoría que, por otra parte, había preocupado enormemente a los apologetas del cristianismo en el siglo XVII ${ }^{46}$, bien conocedores de la enorme carga subversiva que entrañaba. Como afirma Le Vayer en De la philosophie sceptique:

"Ce n'est donc pas hors d'apparence et de probabilité qu'Epicure et Aristippe soustenoient qu'il n'y avoit rien qui fust naturellement juste ou injuste (...) les moeurs despendant absolüment de la coustume, qui justifie et approuve en un lieu, ce qu'elle blasme et condamne en un autre. (...) ...cette vertu mesme que nous chimerisons dans les escholes, n'estant peu-estre qu'un tiltre vain, et un nom servant à l'ambition de ceux qui se disent Philosophes, et qui n'ont encores peu convenir de ce en quoy elle consiste” ${ }^{47}$.

Dado que términos como "virtud" y "vicio" son producto de la costumbre y del juicio fluctuante y desorientado de los hombres, el bien y el mal se convierten en divisa válida sólo en el seno de cada cuerpo cultural. No puede haber acuerdo, como se señala en el diálogo De l'ignorance louable, acerca de virtudes como prudencia, justicia y templanza ${ }^{48}$ porque, en definitiva, la moral carece de fundamento trascendente o universal alguno:

44 De la philosophie sceptique, Dialogues, p. 33 (cursiva nuestra).

45 Cfr. Esbozos pirrónicos, ed. cit., libro I, pp. 97 ss.

46 Vid. Supra, nota 10.

47 De la philosophie sceptique, Dialogues, pp. $42-43$ (cursiva nuestra).

48 Cfr. De l'ignorance louable, Dialogues, pp. 287 ss. No es de extrafiar que la avaricia y la lujuria puedan ser consideradas como valores positivos en algunas culturas (Cfr. op. cit., p. 292). 
"Mais on reconnoist bien tost que toute sa science [en referencia a la moral] va plus à l'ornement et à l'ostentation, qu'à la regle et à la bonne conduitte de nostre vie. Par exemple, elle ne nous rend pas en effet la mort plus douce, ny ses pointes moins sensibles, mais elle nous donne plus d'adresse que nous n'aurions à en dissimuler le ressentiment; de sorte que celuy-là paroistra le plus grand Philosophe moral, qui aura le plus d'artifice à faire valoir son mestier ou son jeu. Ce n'est pas que je m'attache aux actions des particuliers, comme vous disiez, mes argumens ne sont point ad hominem, ils vont contre toute la doctrine des moeurs, qui n'a que l'apparence exterieure, encore toute vacillante, et sans aucun fondement certains ${ }^{49}$.

También la religión es un hecho convencional, una construcción cultural que, cuando se ha administrado con habilidad política y astucia, ha demostrado ser un elemento de control de las mayorías populares en manos de las minorías gobernantes, pero que escapa enteramente de los principios y leyes de la razón. En el importante diálogo De la divinité Le Vayer afirma:

"...tout ce que nous apprenons des Dieux et des religions, n'est rien que ce que les plus habiles hommes ont conceu de plus raisonnable selon leur discours pour la vie morale, oeconomique, et civile, comme pour expliquer les phainomenes des moeurs, des actions, et des pensées des pauvres mortels, afin de leur donner de certaines regles de vivre, exemptes, autant que faire se peut, de toute absurdité. De sorte que s'il se trouvoit encore quelqu'un qui eust l'imagination meilleure que ses devanciers, pour establir de nouveaux fondemens ou hypotheses, qui expliquassent plus facilement tous les devoirs de la vie civile, et generalement tout ce qui se passe parmy les hommes, il ne seroit pas moins recevable avec un peu de bonne fortune, que Copernic et quelques autres en leurs nouveaux systemes, où ils rendent compte plus clairement et plus briefvement de tout ce qui s'observe dans les cieux, puis que finalement une religion, conceuë de la sorte, n'est autre chose qu'un systeme particulier, qui rend raison des phainomenes morales, et de toutes les apparences de nostre douteuse Ethiques" ${ }^{50}$.

La exposición de nuestro autor transita aquí sin apenas apartarse de la senda marcada por Pierre Charron en La Sagesse ${ }^{51}$, senda compartida por el

49 Op. cit., pp. 298-299 (cursiva nuestra).

so De la divinite, Dialogues, pp. 330-331 (cursiva nuestra).

51 Cfr. Charron, P., De la Sagesse, Burdeos, 1601 y París, 1604, reed. Corpus des Oeuvres de Philosophie en langue française, Fayard, Paris, 1986, libro II, V, pp. 445 ss. 
libertinismo erudito de la primera mitad del siglo XVII, en el que como hemos tenido ya ocasión de exponer al principio, el tratamiento de la religión como “instrumentum regni» es uno de los temas recurrentes ${ }^{52}$. En efecto, a juicio de Le Vayer basta con efectuar un estudio comparativo de las diferentes religiones para advertir que nada hay en ellas que no se halle presente en cualquier otro producto humano. Si el conocimiento de la divinidad, nos dice, dependiera de la luz natural no asistiríamos al espectáculo de la divergencia entre unas religiones y otras. Será más prudente reconocer, por tanto, que la confesión religiosa se adquiere por los mismos mecanismos que la lengua o cualquiera de las otras costumbres, esto es, a través de un proceso de socialización:

"et c'est ce qui fait dire si judicieusement à Marc Antonin, racontant ce qu'il avoit retenu de tous ceux qui avoient eu soin de son instruction, qu'en ce qui estoit de la religion, il l'avoit succée avec le laict...." 53 .

Los preceptos y dogmas son muy dispares entre unas y otras religiones, aunque, eso sí, todas han antropomorfizado la divinidad imprimiendo en esa forja de la imagen divina el mismo peculiar estilo que se ha manifestado en otros productos culturales:

"Les uns ont fait des Dieux masles, les autres femelles, Trismegiste et Orphée nous representent le leur Androgyne; et Synilius dit du vrai Dieu dans ses hymnes, quil est pere et mere, masle et femelle tout ensemble" " ${ }^{54}$;

52 Repárese en el siguiente pasaje de Gabriel Naudé, perteneciente a su obra Considérations politiques sur les coups d'État que citamos por la traducción espanola (Consideraciones politicas sobre los golpes de Estado, Estudio Preliminar, traducción y notas a cargo de GÓmEZ RoDRfGUEZ, C., Madrid, 1998): «Como han comprendido perfectamente los legisladores, no hay medio más poderosos para dominar el espíritu de los pueblos que la religión porque, cuando se ha de emprender cualquier empresa, lleva al extremo cuanto se ha de hacer...) (p. 177). Tal planteamiento pertenece a la tradición pomponazziana y maquiaveliana, vinculada a su vez, con el averroísmo. Sobre estas importantes cuestiones Vid. GRANADA, M. A., Cosmologia, religion y politica en el Renacimiento: Ficino, Savonarola, Pomponazzi, Maquiavelo, Barcelona, 1.988; -: "Maquiavelo y Giordano Bruno: religión civil y crítica del cristianismo", Bruniana et Campanelliana, 1998/2, pp. 343-368; -: "Averroes y los averroísmos", Actas del III Congreso Nacional de Filosofia Medieval, Zaragoza, 1.999, pp. 163-182, especialmente pp. 175-176; PINE, M.L., Pietro Pomponazzi: Radical Philosopher of the Renaissance, Padua, Antenore, 1986.

53 LA MOTHE LE VAYER, F., De la divinité, Dialogues, p. 339 (cursiva nuestra).

54 Op. cit., p. 340. 
porque estando la divinidad fuera del alcance del conocimiento humano, todo discurso teológico especulativo pierde ya no el valor de verdad, sino el sentido mismo ${ }^{55}$. De ahí que las imágenes ofrecidas de Dios no deban ser consideradas más que un producto de la imaginación o invención. Todas llevan el sello de su artesano y la impronta de la tradición cultural que las ha hecho posibles:

"Toutes ses apotheoses ont fait naistre une opinion si contraire à l'Eternité Divine, qu'on a soustenu que les hommes estoient bien plus anciens que les Dieux, puis que ceux-cy tenoient leur estre des premiers, et que nous n'adorons point de Divinité que nous n'eussions faite..1 ${ }^{56}$

Si el conocimiento humano no puede acercarnos a la religión, si distorsiona, como acabamos de ver, la imagen de la divinidad, apartando a los hombres de la única noticia de Dios asumible que es la recibida desde la fe, parece claro que la religión es una experiencia que queda al margen de la racionalidad: Será recibida exclusivamente a través de un acto de fe:

"Car ce n'est pas, á mon advis, l'abondance de connoissance, mais bien celle de la grace divine, qui nous peut rendre icy [en materia de religión] clairvoyans; ayant esté fort bien dit, que toute la science, aussi bien que toute la sagesse humaine, ne sont que folie devant Dieun ${ }^{57}$.

Sabemos que Le Vayer reconoce el valor político de la religión, pues hemos dicho ya que acepta su valor instrumental para propiciar una conservación más o menos pacífica del cuerpo político. Ahora bien, frente a autores como Naudé, para quien la buena política hace justo el uso instrumental de la religión, así como otros recursos muy alejados de la moral convencional, como

55 Intentar componer un discurso racional sobre Dios es incurrir en esa enfermedad que afecta al colectivo humano consistente en orientar la curiosidad hacia donde el intelecto no puede llegar. Como afirma en los Soliloques sceptiques: «Cependant c'est une des principales, et des plus ordinaires maladies de l'homme, d'estre travaillé d'une curiosité inquiete pour des choses qu'il ne peut sçavoir, et qu'il lui est vraisemblablement plus avantageux d'ignorer, que d'en prendre connoissance, puisque Dieu a limité la sphere d'activité de son ame, qui ne peut pas penetrer jusques-là." ( Primer Soliloquio, ed. c it., p. 12).

56 LA MOThe le VAYER, F, De la divinite, Dialogues, p. 341.

57 Op. cit., pp. 347-348. Le Vayer parafrasea un célebre pasaje paulino que ha sido muchas veces invocado para subrayar la absoluta superioridad de la fe respecto a la razón (Cfr. S. Pablo, A los Corintios, I, 20). 
por ejemplo, el uso de los golpes de Estado, Le Vayer nunca consideró que la actividad política fuera algo noble y excelente, sino algo muy por debajo de la filosofía; un mal necesario del que ésta se aparta:

"Mais tous conviennent entr'eux, que les plus grands Legislateurs ne se sont servis de l'opinion vulgaire sur ce subject [religión] (laquelle ils ont non seulement fomentée, mais accreuë de tout leur possible) que pour emboucher de ce mords le sot peuple, pour le pouvoir par aprés mener à leur fantaisiens ${ }^{58}$.

Este planteamiento de La Mothe tiene como consecuencia un distanciamiento del filósofo respecto a las convenciones adoptadas por la cultura, incluso en el ámbito moral y religioso. El filósofo se aparta a su gabinete, a la soledad de sus escritos para aparecer como un individuo necesariamente alejado de toda propuesta colectiva, pues la propia tarea filosofica cuestiona los fundamentos de las instituciones y creencias más arraigadas. La escisión entre la esfera de lo público y la esfera de lo privado es aquí muy neta. El individuo se integra en un cuerpo político, en una identidad cultural o bajo una confesión religiosa por unas causas que más tienen que ver con la conservación material que con unos fundamentos trascendentes o susceptibles de convertirse en ciencia. La socialización, en efecto, se consolida a través de la administración política de elementos mitológicos, como la misma religión histórica, los mitos nacionales o las fábulas históricas ${ }^{59}$ por más que éstos aparezcan bajo la faz de un discurso racional y científico. En el fondo La Mothe le Vayer se halla más cerca de pensar que la irracionalidad domina la vida colectiva de los hombres; una irracionalidad, eso sí, que sólo capta el filósofo escéptico, pues las mayorías asumen las convenciones como si se tratase de verdades eternas. El filósofo escéptico, en su retiro, sabe también que si bien el poder no puede legitimarse desde principio filosófico alguno, sí debe ejercerse para evitar la descomposición social y los cambios tumultuosos; sin embargo para esta tarea no debe buscarse la colaboración del filósofo, pues la política es una labor que se ajustará más a aquellos hombres donde la ambición personal se antepone al deseo de conocimiento. Como concluye en su diálogo De la philosophie sceptique:

58 De la divinité, Dialogues, pp. 318-319 (cursiva nuestra).

59 De hecho, la historia no puede aspirar más que a convertirse en una fábula, en un modelo moral cuyo objetivo es eminentemente pedagógico y propiciatorio de la cohesión social, nunca podrá alcanzar un estatuto estrictamente científico. Sobre ello Vid. BORGUERO, C., La certezza e la storia. Cartesianesimo, pirronismo e conoszenza storica, ed. cit., pp. 48 ss. 
"Voilà donc ce bon sens, ou ce bon esprit dont on se veut tant prevaloir, qui n'est plus d'usage que dans le desert et la solitude, puis que dans le cours et le traffic de la vie civile, il passe pour marchandise de contrebande, ou pour monnoye deffenduë, et qui n'est de mise, plustost capable de vous nuire et mettre en peine, que de vous servir en vos affaires et au besoin" ${ }^{60}$.

Vemos que Le Vayer aparta la política y la religión de la esfera de la racionalidad; las deja muy lejos de quienes desean cultivar las más altas funciones del espíritu. Precisamente el ejercicio de la filosofía daba como resultado un desenmascaramiento de los mitos en los que se apoyan la una y la otra. A su juicio, el proyecto colectivo invocado por los políticos no tiene otras miras que la mera conservación y, por eso, su postura en esta materia se halla lejanísima del ideal platónico que pretendía hermanar la filosofía con la vida pública. Pero también se encuentra muy apartada de quienes pretendían a través de la razón de Estado conferir racionalidad al ejercicio del poder y a la constitución y funcionamiento del cuerpo político. Por otra parte, sabemos ya que si se trata de religión el discurso de Le Vayer es estrictamente fideísta. En consecuencia, al escéptico no le queda más remedio que optar por un retiro voluntario, más acorde con su función de filósofo, donde la libertad de pensamiento es condición necesaria, por más que ello suponga un distanciamiento intelectual y moral de la tradición y de los fundamentos en los que se basa la vida pública. Como dice en el diálogo De la vie privée:

"Les voeux de mes parens m'y avoient attaché à mille servitudes, la Philosophie m'y a mis en pleine et veritable liberté. Les loix et coustumes sembloient m'y obliger à des actions honteusement laborieuses, la Philosophie m'en a exempté, et m'a comblé de repos et de felicité; summa beatae, solida tranquilitas, et ejus inconcussa fiducia (Séneca, Ep. 44). Et vous trouvez estranges mes façons de faire? Vous trouvez blasmable ma solitude? Vous estimez honteuse ma retraite? Ma condition pauvre et cherifve? Ma tranquillité faineante et reprochable? Mes plaisirs imaginaires ou extravagants? Voulez-vous pour un peu de temps vous servir de vostre raison naturelle, et je ne prendray point d'autre juge que vous-mesme de tout nostre different?" ${ }^{61}$.

60 LA MOTHE LE VAYER, F, De la philosophie sceptique, Dialogues, p. 49.

61 La Mothe le Vayer, F., De la vie privée, Dialogues, pp. 145-146. 
$\mathbf{V}$

Se ha escrito mucho acerca del estilo de La Mothe y de su acoplamiento con los planteamientos libertinos ${ }^{62}$. Su obra aparece en forma de diálogos, de cartas, de homilías, soliloquios o pequeños discursos. En algunas ocasiones ha querido publicarlas bajo seudónimo ${ }^{63}$, pero, en cualquier caso, debemos señalar el carácter críptico que recorre sus escritos; éstos permiten a menudo, por lo menos, una doble lectura. Él mismo parece querer ofrecer unas claves o un mensaje entrelineado y más hondo a los lectores dotados de un espíritu más libre y una mayor capacidad de penetración. En la Lettre de l'auteur previa a los Dialogues él mismo escribe:

"La liberté de mon stile mesprisant toute contrainte, et la licence de mes pensées purement naturelles, sont aujourd'huy des marchandises de contrabande, et qui ne doivent estre exposées au public" ${ }^{64}$.

De hecho, esta peculiaridad no sólo es específica en La Mothe, sino que constituye uno de los rasgos que caracterizan el libertinismo erudito, como se ha repetido unánimemente desde la publicación de la clásica obra de René Pintard, Le Libertinage érudit.... El mismo Gabriel Naudé encabeza las Consideraciones politicas sobre los golpes de Estado de un modo muy similar:

"Este libro no ha sido compuesto para complacer a todo el mundo; si el autor hubiera tenido essa intención no lo habría escrito al estilo de Montaigne y Charron, del cual bien conoce que muchas personas se apartan con disgusto a causa del gran número de citas latinas que conlleva» ${ }^{65}$,

obra que, no lo olvidemos, se publicó en 1639 también anónimamente. Las causas de un desvelamiento tan restringido del verdadero pensamiento apuntan al contenido subversivo del mismo, a su difícil asimilación por parte de

62 Sobre ello Vid. Gros, J.M., "Le masque du scepticisme chrétien chez La Mothe Le Vayer ", ed. cit.

63 Recordemos que los Dialogues se publicaron bajo el nombre de Orasius Tubero. Vid. PINTARD, R., Le libertinaje érudit..., ed. cit., pp. 131 ss.

64 Lettre de 'lauteur, Dialogues, ed. cit., p. 11.

65 NAUDE, G., Consideraciones politicas sobre los golpes de Estado, ed. cit., p. [3]. 
unas mayorías que, además, necesitan la aceptación de otro tipo de verdades que facilitarán su integración cohesionada en la vida social. Le Vayer en su diálogo De la divinité hace hincapié en la calculada ambigüedad o, más bien, en la duplicidad de sentidos que los grandes pensadores han impreso a sus escritos por mor de esta incapacidad para una clara recepción de la verdad de la que adolece una gran mayoría de los hombres:

"Aussi veulent-ils [algunos filósofos] que les plus grands hommes se soient assez apperceus de cette imposture divine, s'il faut ainsi parler, quoy que depuis Socrate l'apprehension de la ciguë les ait tenus dans le silences ${ }^{66}$.

En cuanto al fideísmo de Le Vayer, casi tan repetido como su escepticismo, ¿debe considerarse como una máscara que permite desarrollar un análisis crítico de la religión histórica? ${ }^{67}$ Más que entrar en una consideración directa acerca de la sinceridad del fideísmo de Le Vayer, debemos destacar en cambio la dificultad de conciliación que entraña su planteamiento filosófico con el cristianismo. En primer lugar, su defensa de la libertad individual imbricada en su programa escéptico, su énfasis en la superioridad de esta "sagesse" respecto a cualquier sistema moral; la concepción de la filosofía como mirada lúcida que deja al descubierto el componente de inestabilidad que afecta a todo conocimiento, son hechos que debemos complementar con otras evidencias en los planteamientos de nuestro autor. En este sentido, no olvidemos que para La Mothe la costumbre es el único elemento capaz de conferir estabilidad a los asuntos humanos; que la aceptación de mitos es un hecho necesario para la pervivencia más o menos armoniosa del colectivo humano. Todo ello confiere a su fideísmo una naturaleza muy distinta de la que se deriva, por ejemplo, de los planteamientos de Pascal y los jansenistas. Cuando la filosofía estri-

66 La MOTHE le VAYER, De la divinité, Dialogues, p. 320 (cursiva nuestra). Naudé, por su parte, señala en referencia al tiraje minoritario de sus Consideraciones politicas: "Sé perfectamente que tal número es demasiado pequeño para que este libro alcance la notoriedad de Le Prince de Balzac y Le Ministre de Silhon. Pero como los temas que trata son mucho más importantes, será forzoso que no sean tan comunes." (Op. cit., p. [3], cursiva nuestra).

${ }^{67}$ Frente a la posición de R. Popkin, que se inclina por aceptar el fideísmo de La Mothe como una expresión sincera de religiosidad, otros autores (T. GREGORY, J. M. GROS, D. TARANTO o S. GIOCANTI, entre otros) cuestionan su fideísmo o lo interpretan como un ejercicio de simulación (caso de J. M GROS en su obra "Le masque du scepticisme chrétien chez La Mothe Le Vayer", ed. cit.). 
ba en retirar la máscara, en un minucioso trabajo de desmitificación y desvelamiento, cuando la sabiduría consiste en descubrir los resortes y el trasfondo que subyace tras los actos más sacralizados o mitificados en el gran teatro del mundo, parece comprensible el mantenimiento de un doble discurso, pues conocer una verdad que deja al descubierto la debilidad de los fundamentos de instituciones humanas que dan soporte a la propia sociedad no es una verdad que puedan aceptar todos. 